Check for updates

Cite this: RSC Adv., 2019, 9, 1476

\title{
B, N-dual doped sisal-based multiscale porous carbon for high-rate supercapacitors $\uparrow$
}

\author{
Heng Wu, (D) a Wenyu Yuan, (D) a Yingxin Zhao, ${ }^{a}$ Daoyang Han, ${ }^{a}$ Xiaowen Yuan*b \\ and Laifei Cheng *a
}

B, N dual-doped sisal-based activated carbon (BN-SAC) with a multiscale porous structure for high-rate supercapacitor electrode was prepared through a novel and facile strategy. With the inherent cellular channels serving as primary macropores, secondary mesopores and micropores are generated on the fiber surface and tracheid walls through low-pressure rapid carbonization of $\left(\mathrm{NH}_{4}\right)_{2} \mathrm{~B}_{4} \mathrm{O}_{7}$-containing sisal fibers and successive $\mathrm{KOH}$ activation. In addition to introducing $\mathrm{B}, \mathrm{N}$ atoms into the $\mathrm{BN}-\mathrm{SAC}$, the additive also facilitates the formation of mesopores due to the rapid gas evaporation during its decomposition, leading to significantly increased specific surface area $\left(2017 \mathrm{~m}^{2} \mathrm{~g}^{-1}\right.$ ) and mesoporosity (68.6\%). As a result, the BN-SAC-3 shows highly enhanced electrochemical performance including a high specific capacitance of $304 \mathrm{~F} \mathrm{~g}^{-1}$, excellent rate capability (with $72.6 \%$ retention at $60 \mathrm{~A} \mathrm{~g}^{-1}$ ) and superior cycling stability $(4.6 \%$ capacitance loss after 3000 cycles). After assembling the BN-SAC-3 into symmetric supercapacitor, it shows a specific capacitance of $258 \mathrm{~F} \mathrm{~g}^{-1}$ at $1 \mathrm{~A} \mathrm{~g}^{-1}$ with $76.4 \%$ retention at $40 \mathrm{~A} \mathrm{~g}^{-1}$ in $6 \mathrm{M} \mathrm{KOH}$ electrolyte, and delivers a maximum energy density of $24.3 \mathrm{~W} \mathrm{~h} \mathrm{~kg}^{-1}$ at a power density of $612.8 \mathrm{~W} \mathrm{~kg}^{-1}$ in $1 \mathrm{M} \mathrm{TEABF}_{4} / \mathrm{AN}$ electrolyte. This work provides a new strategy for the synthesis of multiscale porous ACs for high-performance supercapacitors or other energy storage and conversion devices and is expected to be applied on other biomasses for large-scale production.

Received 24th November 2018 Accepted 6th January 2019

DOI: 10.1039/c8ra09663e

rsc.li/rsc-advances always possess disordered porous textures and abundant small micropores (mainly $<0.6 \mathrm{~nm}$ ) both of which would significantly reduce the accessible surface area for electrolyte ions. ${ }^{11,12}$ As a result, the ACs-based electrodes typically show limited specific capacitance $\left(<10 \mu \mathrm{F} \mathrm{cm}^{-2}\right)$ and inferior rate capability (sharply reduced specific capacitance at high current densities), despite having ultrahigh SSA of up to $2000-3000 \mathrm{~m}^{2} \mathrm{~g}^{-1}$. $^{13,14}$ To solve these problems, efforts have been devoted on novel preparation methods combining various pretreatment processes and common activation to produce ACs with both high SSA and high ratio of mesopores, thus resulting in high specific capacitance and high rate performance. ${ }^{15-19}$ For example, through combining hydrothermal and $\mathrm{KOH}$ activation, ACs with high SSA $\left(3037 \mathrm{~m}^{2} \mathrm{~g}^{-1}\right)$ and high mesoporosity $(>82 \%)$ were prepared from lotus pollen, and exhibited a high capacitance of $207 \mathrm{~F} \mathrm{~g}^{-1}$ and superior capacitance retention of about $190 \mathrm{~F} \mathrm{~g}^{-1}$ at $10 \mathrm{~A} \mathrm{~g}^{-1} \cdot{ }^{10}$ However, in spite of the ratios of meso/micropore are tunable in these novel ACs, the disordered pore structures with randomly distributed mesopores and micropores still hinder the full utilization of all-level pores.

Recent molecular dynamic simulations and experimental results suggest that carbon materials with multiscale pores, especially with hierarchical macro-meso-microporous structures can facilitate ion diffusion at ultrahigh current densities. ${ }^{\mathbf{2 0}-22}$ With primary macropores serving as electrolyte reservoirs and secondary mesopores as buffer zone, the
${ }^{a}$ Northwestern Polytechnical University, China. E-mail: chenglf@nwpu.edu.cn ${ }^{b}$ Massey University, New Zealand. E-mail: xw.yuan@massey.ac.nz

$\dagger$ Electronic supplementary information (ESI) available. See DOI: 10.1039/c8ra09663e 
unobstructed hierarchical channels with highly shorted diffusion distance make the diffusion of ions into/out of the nearby micropores easier and rapider, giving rise to outstanding capacitance and rate capability. ${ }^{23,24}$ Previous attempts on achieving such multiscale porous structures always rely on complicated and uneconomical template method. ${ }^{22,25}$ With the rapid development of nanocarbon materials such as CNTs and graphene, creating regular macroscopic assembles including fibers, films and foams with individual CNTs and graphene seem to be another promising way for multiscale porous structures. ${ }^{26-28}$ Unfortunately, these nano-sized individuals always encounter with problems such as high cost and inevitable agglomeration during assembling. ${ }^{2,29}$ In addition, the relatively low density of electrodes based on CNTs and graphene also restrict their wider application in EDLCs due to lower volumetric specific capacitance compared with ACs. ${ }^{30}$ Therefore, it is highly demanded to develop novel preparation methods for ACs with both high SSA and hierarchical multiscale porous structures, especially in a simple and economical way.

Besides optimizing porous structure, heteroatoms doping (i.e., nitrogen $(\mathrm{N})$, oxygen $(\mathrm{O})$, boron $(\mathrm{B})$, phosphorus $(\mathrm{P})$, sulfur (S) doping) has also been regarded as an effective method to improve the electrochemical performance of ACs, owing to the introduced pseudocapacitance, increased electrical conductivity and improved surface wettability of pore walls. ${ }^{31-36}$ Compared with single-atom doping, recent researches focus more on dual-atom doping as which could take advantages of two different heteroatoms in addition to inducing synergistic effect. $^{37-39}$ In fact, it has been proven that $\mathrm{B}, \mathrm{N}$ dual-doping could remarkably increase the surface area, active sites and interlayer distance of carbon. ${ }^{\mathbf{4 0 , 4 1}}$ As a result, it seems to be an ideal strategy to co-dope $\mathrm{B}$ and $\mathrm{N}$ atoms into multiscale porous ACs for high-performance EDLCs electrodes.

Benefiting from their high yield, cost effectiveness and environmental friendliness, biomasses have widely been employed as precursors for ACs. ${ }^{42-47}$ As one promising but less explored biomasses for such application, sisal fibers simultaneously possess high tensile strength, high ratio of length to diameter, high yield of carbonization and short growth periodicity. ${ }^{45,46}$ Different from various natural fibers such as jute, flax, hemp, cotton and ramie, sisal fibers are especially characterized with honeycomb texture constructed by abundant parallel distributed tracheids. ${ }^{15-17}$ The unique honeycomb structure is quite beneficial for the development of hierarchical porous structure, while previous studies merely employed sisal fibers as common precursors of ACs. ${ }^{\mathbf{4 4 , 4 6 4 8 - 5 0}}$ Herein, for the first time, we report a novel method to prepare B, N dual-doped ACs with multiscale porous structure from sisal fibers for highperformance EDLCs. With unique cellular channels serving as primary macropores, secondary mesopores are generated on fiber surface and tracheid walls through rapid carbonization of sisal fibers with $\mathrm{B}, \mathrm{N}$-containing reagent under low pressure, followed by $\mathrm{KOH}$ activation which further create micropores on mesopore walls. Notably, the infiltrated $\left(\mathrm{NH}_{4}\right)_{2} \mathrm{~B}_{4} \mathrm{O}_{7}$ not only endow the as-obtained ACs with $\mathrm{B}, \mathrm{N}$ dual-doping, it also facilitates the formation of secondary mesopores due to the rapid gas evaporation during its decomposition. Benefitting from their hierarchical macro-meso-microporous structure with both high SSA and mesoporosity, as well as B, N dualdoping which provides pseudocapacitance and improves electrical conductivity, the BN-SAC-3 exhibits excellent electrochemical performance including a high specific capacitance of $304 \mathrm{~F} \mathrm{~g}^{-1}$ at $1 \mathrm{~A} \mathrm{~g}^{-1}$ with $72.6 \%$ retention at $60 \mathrm{~A} \mathrm{~g}^{-1}$ and excellent cycling stability (4.6\% capacitance loss after 3000 cycles). Moreover, the BN-SAC-3 in a symmetric supercapacitor with $6 \mathrm{M} \mathrm{KOH}$ as electrolyte shows a specific capacitance of 258 $\mathrm{F} \mathrm{g}^{-1}$ at $1 \mathrm{~A} \mathrm{~g}^{-1}$ with $76.4 \%$ retention at $40 \mathrm{~A} \mathrm{~g}^{-1}$, and delivers a maximum energy density of $24.3 \mathrm{~W} \mathrm{~h} \mathrm{~kg}^{-1}$ at a power density of $612.8 \mathrm{~W} \mathrm{~kg}^{-1}$ in $1 \mathrm{M} \mathrm{TEABF}_{4} / \mathrm{AN}$ electrolyte.

\section{Experimental section}

\subsection{Materials}

Unbleached sisal fibers were purchased from Guangdong Dongfang Sisal Group Co. Ltd. (China). Before use, the fibers were boiled with deionized water for 2 hours. $\left(\mathrm{NH}_{4}\right)_{2} \mathrm{~B}_{4} \mathrm{O}_{7} \cdot 4 \mathrm{H}_{2} \mathrm{O}$ (AR, Sigma-Aldrich), potassium hydroxide (AR, Sigma-Aldrich), carbon black (TIMCAL SUPER P LI), poly-tetrafluoroethylene (PTFE, DAIKIN), tetraethylammonium-tetrafluoroborate/ acrylonitrile $\left(\mathrm{TEABF}_{4} / \mathrm{AN}, \mathrm{CAPCHEM}\right)$ and separator films (MPF30AC and TF4840, NKK) were all used as received.

\subsection{Fabrication of the BN-SAC-n}

The sisal fibers were cut into short fibers ( $\sim 30 \mathrm{~mm}$ length) and immersed into aqueous solution of $\left(\mathrm{NH}_{4}\right)_{2} \mathrm{~B}_{4} \mathrm{O}_{7} \cdot 4 \mathrm{H}_{2} \mathrm{O}(0.04$, 0.08 and $0.16 \mathrm{M}$ ) for one day under continuous stirring at room temperature. After the sisal fibers were fully dried in an electric oven, they were subjected to a two-step process to prepare $\mathrm{BN}$ SAC- $n$. First, $3.0 \mathrm{~g}$ of sisal fibers were placed in a rapid thermal processing furnace (BTF-1200C-RTP-S90B, $10 \mathrm{~kW}$, AnHui BEQ Equipment Technology Co., Ltd) powered by infrared-heating. Under continuous vacuuming for a low furnace pressure (below $10 \mathrm{kPa}$ ), the fibers were heated to $800{ }^{\circ} \mathrm{C}$ with a high heating rate of $100{ }^{\circ} \mathrm{C} \mathrm{min}^{-1}$ and maintained for $2 \mathrm{~h}$. The asobtained products were then immersed in $1 \mathrm{M} \mathrm{KOH}$ aqueous solution overnight. After fully dried in an electric oven, the $\mathrm{KOH}$-treated BN-SC were annealed in the same RTP at $800{ }^{\circ} \mathrm{C}$ for $1 \mathrm{~h}$ in flowing nitrogen atmosphere (with flow rate of 0.15 $\mathrm{L} \min ^{-1}$ ). After that, the sample was thoroughly washed with $1 \mathrm{M} \mathrm{HCl}$ and plenty of de-ionized water until the pH was 7 . Finally, the product was dried at $90{ }^{\circ} \mathrm{C}$ overnight and denoted as BN-SAC- $n$, where $n$ (1, 2 and 3) denotes the concentration of $\left(\mathrm{NH}_{4}\right)_{2} \mathrm{~B}_{4} \mathrm{O}_{7}$ aqueous solution $(0.04,0.08$ and $0.16 \mathrm{M})$. For comparison, the sisal-based $\mathrm{AC}$ without $\mathrm{B}, \mathrm{N}$ doping was prepared through traditional carbonization process $\left(800^{\circ} \mathrm{C}\right.$ for $1 \mathrm{~h}$ with a heating rate of $5{ }^{\circ} \mathrm{C} \mathrm{min}^{-1}$ under atmospheric pressure in flowing nitrogen atmosphere) and the same activation strategy, denoted as SAC.

\subsection{Preparation of supercapacitor cells}

The two-electrode symmetric supercapacitors (SSCs) with our BN-SAC-3 as active materials were fabricated as follows: active materials, carbon black and PVDF were homogeneously mixed 
with a mass ratio of $85: 10: 5$ in the agate mortar, followed by casting the mixture on the current collectors (aluminum foil coated with carbon) with a thickness of 100-120 $\mu \mathrm{m}$. After dried at $120{ }^{\circ} \mathrm{C}$ overnight under vacuum, the electrode were cut into round pieces with diameter of $16 \mathrm{~mm}$ and mass loading of about $1 \mathrm{mg} \mathrm{cm}^{-2}$. The prepared electrodes/collectors were then transferred into an Ar-filled glovebox (the content of water and oxygen were both controlled below $0.1 \mathrm{ppm}$ ) to symmetrically assemble two-electrode supercapacitors, employing $1 \mathrm{M}$ $\mathrm{TEABF}_{4} / \mathrm{AN}$ as electrolyte and TF4840 as separator.

\subsection{Physical characterization}

The morphology of the samples was characterized with a Hitachi S-4700 Field Emission Scanning Electron Microscopy (FESEM) at an acceleration voltage of $15 \mathrm{kV}$ and a Themis Z F-30 Double Cs Corrector Transmission Electron Microscope (TEM) at an acceleration voltage of $300 \mathrm{kV}$. Nitrogen adsorption/ desorption test was carried out with a Micromeritics ASAP 2020 apparatus at $77 \mathrm{~K}$. The $S_{\mathrm{BET}}$ was obtained using the Brunauer-Emmett-Teller (BET) method from adsorption data in the relative pressure $\left(P / P_{0}\right)$ ranging from 0.05 to 0.3 , and the total pore volumes were acquired from the amount of nitrogen adsorbed at a relative pressure of 0.99 . The pore size distribution, micropore volume and mesopore volume were calculated from the nitrogen adsorption/desorption data using the NonLocal Density Functional Theory (NL-DFT) software (SAIEUS, Micromeritics Instrument) with a 'Heterogeneous Surface' model. The X-ray diffraction (XRD) measurements were performed on a Bruker D8 Advance diffractometer with $\mathrm{Cu} \mathrm{K} \alpha$ radiation $(k=0.1542 \mathrm{~nm}, 40 \mathrm{kV})$. The Raman spectra were obtained by a Renishaw-inVia Confocal Raman Microscope using excitation wavelength at $514.5 \mathrm{~nm}$. The chemical composition was studied by X-ray photoelectron spectroscopy (XPS) using a Thermo Scientific X-ray photoelectron (K-alpha).

\subsection{Electrochemical measurements}

All the electrochemical measurements were carried out at room temperature. Before measurements, the working electrodes were soaked into $6 \mathrm{M} \mathrm{KOH}$ electrolyte overnight. For threeelectrode test, the work electrode was prepared through coating the mixture consisting of active materials, PTFE (with a mass ratio of $90: 10$ ) and a small amount of ethanol onto nickel foam followed by drying it at $100{ }^{\circ} \mathrm{C}$ overnight, a $\mathrm{Hg} / \mathrm{HgO}$ was employed as reference electrode and a platinum plate were employed as counter electrodes electrode, and $6 \mathrm{M}$ aqueous $\mathrm{KOH}$ solution was used as electrolyte. The cyclic voltammetry (CV), galvanostatic charge-discharge and electrochemical impedance spectroscopy (EIS) analysis were all performed on a CHI660E electrochemical workstation (Shanghai Chen Hua Co., Ltd, China). The CV and galvanostatic charge-discharge tests were performed in a voltage window of -1.0 to $0 \mathrm{~V} \mathrm{vs.} \mathrm{Hg}$ / $\mathrm{HgO}$ electrode at scan rates of $10-400 \mathrm{mV} \mathrm{s}^{-1}$ and current densities of 1-60 $\mathrm{A} \mathrm{g}^{-1}$, respectively. The EIS measurements were conducted under open circuit potential in the frequency range of $10 \mathrm{mHz}$ to $100 \mathrm{kHz}$ with $5 \mathrm{mV}$ AC amplitude.
The specific capacitance $\left(C_{\mathrm{g}}, \mathrm{F} \mathrm{g}^{-1}\right)$ of work electrode was calculated based on galvanostatic charge-discharge curves according to eqn (1) for three-electrode test and (2) for twoelectrode test:

$$
\begin{aligned}
& C_{\mathrm{g}}\left(\mathrm{F} \mathrm{g}^{-1}\right)=\frac{I}{(\mathrm{~d} v / \mathrm{d} t) \times m} \\
& C_{\mathrm{g}}\left(\mathrm{F} \mathrm{g} \mathrm{g}^{-1}\right)=\frac{2 I}{(\mathrm{~d} v / \mathrm{d} t) \times m}
\end{aligned}
$$

where $I(\mathrm{~A})$ is the discharge current, $m(\mathrm{~g})$ is the mass of active material in each work electrode, $\mathrm{d} v / \mathrm{d} t$ is the slope of the discharge curve after voltage drop (IR drop). The energy density $E\left(\mathrm{~W} \mathrm{~h} \mathrm{~kg}^{-1}\right)$ and power density $P\left(\mathrm{~W} \mathrm{~kg}^{-1}\right)$ (based on the total mass of two electrodes) were calculated using the following equations of (3) and (4):

$$
\begin{gathered}
E=\frac{C_{\mathrm{g}} \times V^{2}}{2 \times 4 \times 3.6} \\
P=\frac{E \times 3600}{\Delta t}
\end{gathered}
$$

where $V$ is the cell voltage after ohmic drop (V) and $t$ is the discharge time (s).

\section{Results and discussion}

\subsection{Fabrication of the BN-SAC- $n$}

The schematic description of the fabrication process for $\mathrm{BN}$ SAC- $n$, the SEM images and TEM image of BN-SAC-3 are illustrated in Fig. 1. As is shown, the $\left(\mathrm{NH}_{4}\right)_{2} \mathrm{~B}_{4} \mathrm{O}_{7}$-containing sisal fiber is characterized by typical honeycomb texture (Fig. 1a, $\mathrm{a}_{1}$ and d) inherited from raw sisal fibers (Fig. S2, ESI†) constructed by parallel distributed tracheids with abundant stomas (Fig. 1e) on both fiber surface and inner cellular walls. As the rapid gas evaporation from sisal fiber and $\left(\mathrm{NH}_{4}\right)_{2} \mathrm{~B}_{4} \mathrm{O}_{7}$ during lowpressure rapid carbonization is facilitated by the unique cellular structure and cannot be in consistent with the rate of fiber dimensional shrinkage, large mesopores and a few macropores are thus uniformly generated on the fiber surface and inner cellular walls (Fig. $1 \mathrm{~b}, \mathrm{~b}_{1}$ and $\mathrm{f}-\mathrm{h}$ ). After further $\mathrm{KOH}$ activation, abundant micropores are etched on every surface of the fiber (Fig. 1h), resulting in a hierarchical macro-mesomicroporous structure with undamaged fiber structural integrity.

The detailed porous structure of all samples were studied by nitrogen adsorption-desorption technique (Fig. 2 and Table 1). As shown in Fig. 2a, the BN-SC shows characteristic type IV isotherm plots with an obvious hysteresis loop located at relative pressure $\left(P / P_{0}\right)$ between 0.5 and 1.0, indicating its welldeveloped mesoporous structure with a SSA of $94 \mathrm{~m}^{2} \mathrm{~g}^{-1}$ and mesoporosity of $93 \% .^{\mathbf{1 3 , 5 1}}$ For the BN-SAC- $n$ which went through further $\mathrm{KOH}$ activation, all profiles show hybrid type I/IV isotherm plots with evident hysteresis loops located at relative pressure $\left(P / P_{0}\right)$ higher than 0.4 , indicating the formation of hierarchical macro-meso-microporous structures with abundant mesopores. Notably, as the amount of $\left(\mathrm{NH}_{4}\right)_{2} \mathrm{~B}_{4} \mathrm{O}_{7}$ 


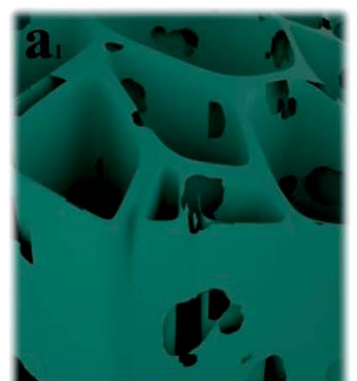

a

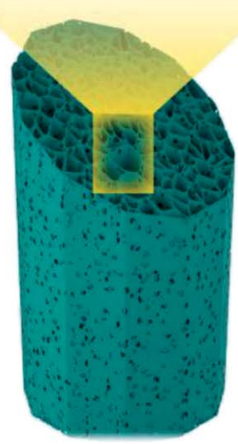

$\left(\mathrm{NH}_{4}\right)_{2} \mathrm{~B}_{4} \mathrm{O}_{7}$-Containing Sisal Fiber

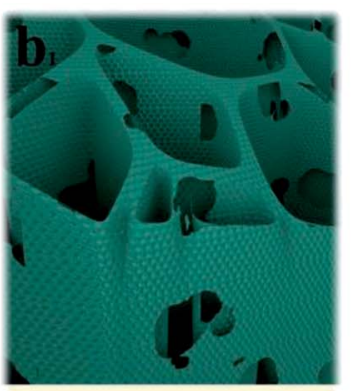

b

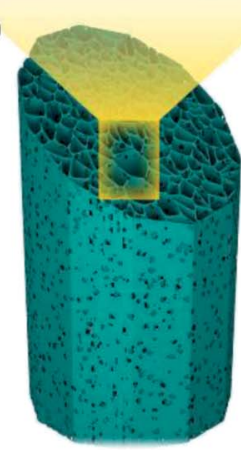

BN-SC
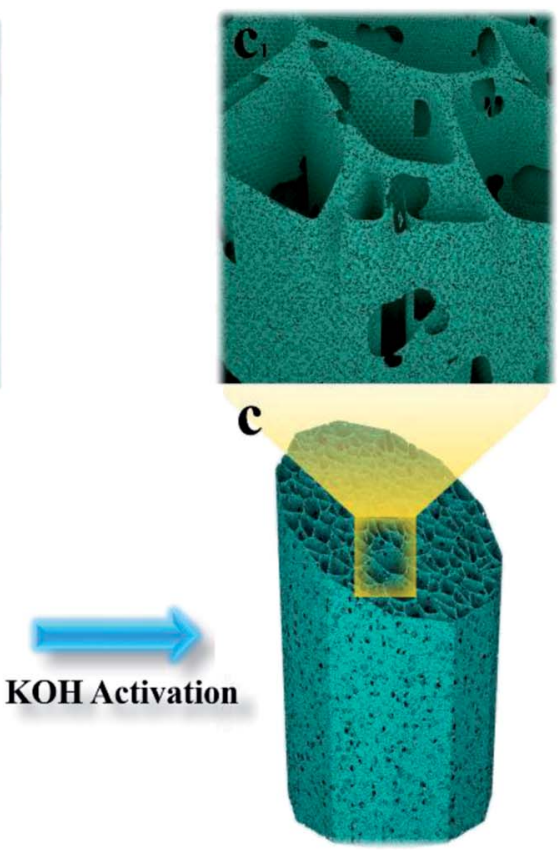

BN-SAC
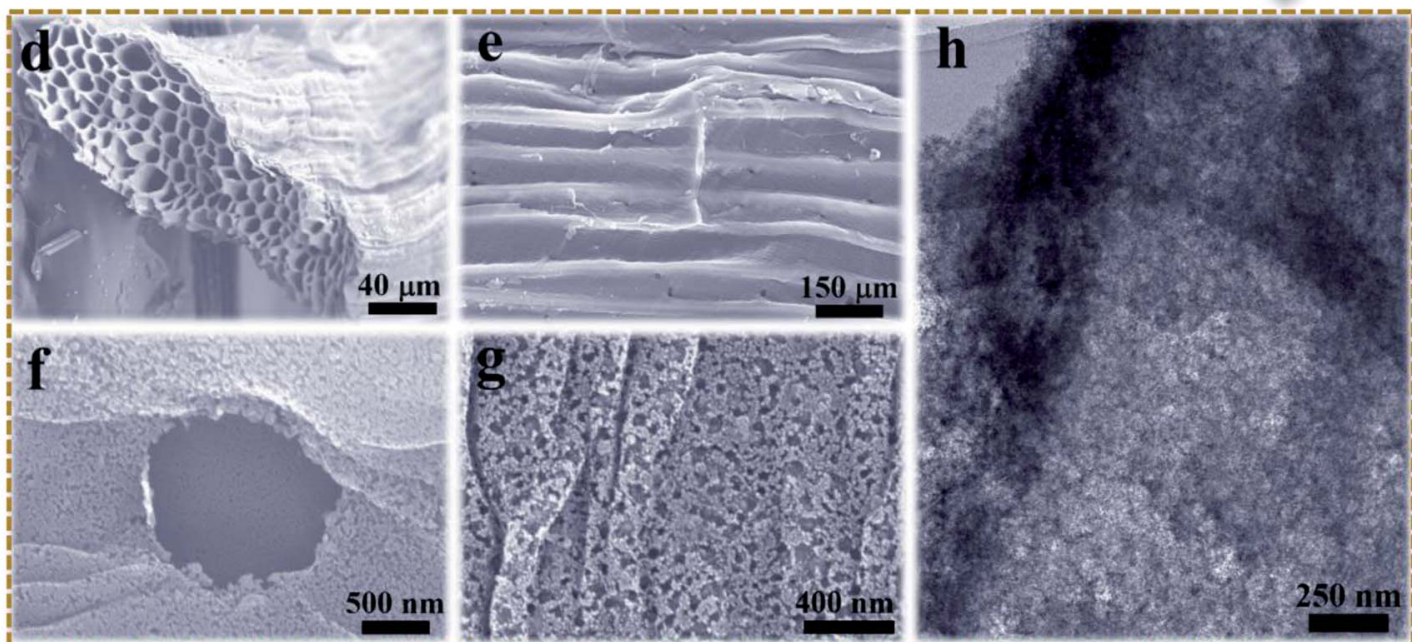

Fig. 1 (a-c and $\left.a_{1}-c_{1}\right)$ Schematic illustration of the synthetic procedure for BN-SAC- $n$; $(d-g)$ SEM images of the BN-SAC-3 showing the crosssection (d), surface with stomas (e) and magnified surface with a stoma (f) and macro/mesopores (g), TEM of the BN-SAC-3 showing the mesopores and micropores.

increases, both of the hysteresis loops and slope of isotherm plots increase, suggesting the rapid development of mesopores and SSA in BN-SAC- $n$ series. As shown in Table 1 , the mesopore volume is $0.71 \mathrm{~cm}^{3} \mathrm{~g}^{-1}$ for BN-SAC-1, $1.09 \mathrm{~cm}^{3} \mathrm{~g}^{-1}$ for BN-SAC-2, and $1.33 \mathrm{~cm}^{3} \mathrm{~g}^{-1}$ for BN-SAC-3, while the micropore volume goes through slight decrease. As a result, the mesoporosity is significantly enhanced from 52.2 to 64.5 and $68.6 \%$ for BN-SAC1, BN-SAC-2 and BN-SAC-3, respectively. In addition to mesopores, the corresponding SSA also increases with the doping level, going from $1802 \mathrm{~m}^{2} \mathrm{~g}^{-1}$ for BN-SAC-1, to $1978 \mathrm{~m}^{2} \mathrm{~g}^{-1}$ for BN-SAC-2, and $2017 \mathrm{~m}^{2} \mathrm{~g}^{-1}$ for BN-SAC-3. Possible explanation for this change is the gas evaporation from $\left(\mathrm{NH}_{4}\right)_{2} \mathrm{~B}_{4} \mathrm{O}_{7}$ decomposition is promoted at high concentration, resulting in more large pores and higher surface area both of which are beneficial for further $\mathrm{KOH}$ activation. ${ }^{40,41}$ The yield of sisal fibers after carbonization and activation is also in good accordance with the nitrogen adsorption-desorption tests, the yield of BNSAC-1, BN-SAC-2 and BN-SAC-3 respectively decreases from 22.0 to 20.3 and $19.4 \%$ with the increasing concentration of $\left(\mathrm{NH}_{4}\right)_{2} \mathrm{~B}_{4} \mathrm{O}_{7}$. In contrast, the SAC prepared through traditional carbonization and activation shows typical type I isotherm plots characterized with microporous structure, exhibiting relatively 

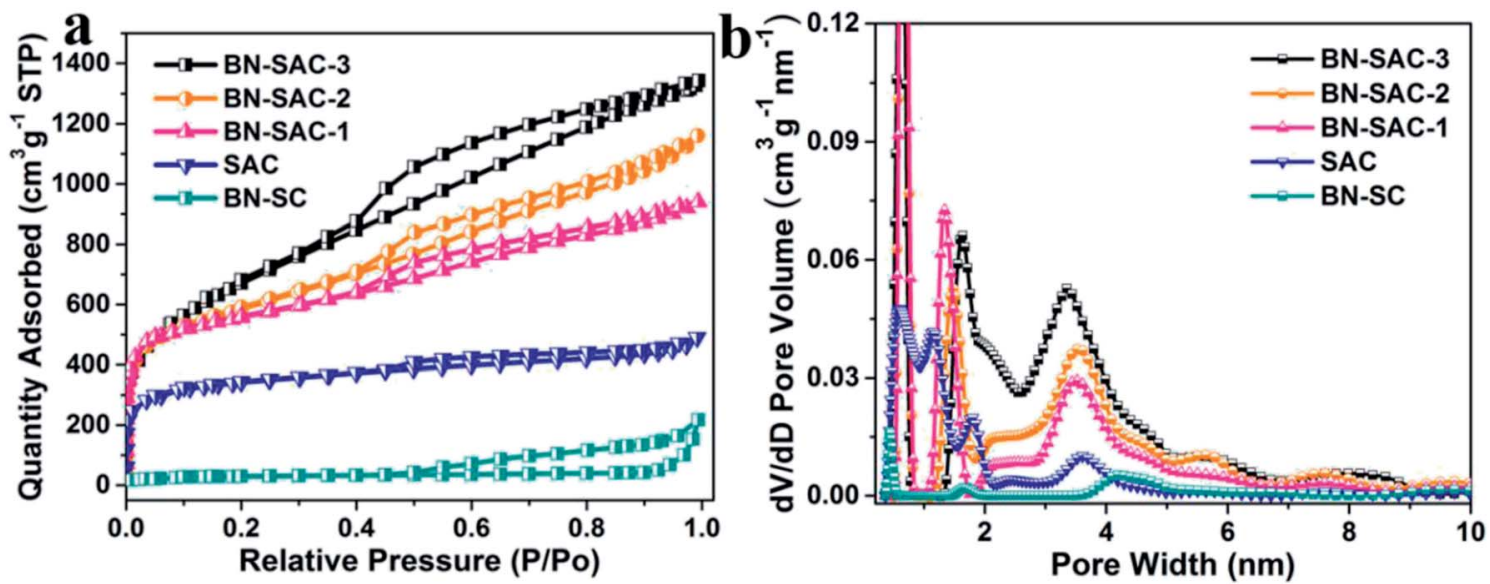

Fig. 2 (a) Nitrogen adsorption/desorption isotherms of SAC, BN-SC and BN-SAC- $n$ series at $77 \mathrm{~K}$; (b) pore size distribution of SAC, BN-SC and $\mathrm{BN}-\mathrm{SAC}-n$ series.

low mesoporosity of $36.6 \%$ and SSA of $1017 \mathrm{~m}^{2} \mathrm{~g}^{-1}$, as well as a higher yield $(27.6 \%)$ than BN-SAC- $n$ series.

The pore size distribution of all samples were calculated using the NLDFT method and the results are shown in Fig. $2 b$. The BN-SAC- $n$ series all exhibit multiscale porous structure with pore size centering at $\sim 0.6,1.4-1.6, \sim 3.5, \sim 5.6$ and $7.5-8.2 \mathrm{~nm}$. It is apparent the average size of pores and pore volume above $2 \mathrm{~nm}$ progressively increase with the doping level, which is in accordance with the results of isotherm plots. Notably, pore volume above $4 \mathrm{~nm}$ is well developed for BN-SAC-3 due to more rapid gas evaporation, showing great potential in high-rate capacitance. In contrast, the pore sizes of SAC are mainly centering below $2 \mathrm{~nm}$ at $0.6,1.1$ and $1.8 \mathrm{~nm}$.

The SEM images of BN-SC and BN-SAC- $n$ series are shown in Fig. S2 (ESI) $\dagger$ and 3. Obviously, the surface and inner cellular walls of BN-SC both show abundant uniformly distributed mesopores and a few macropores (Fig. S2, ESI $\dagger$ ) which are probably produced during low-pressure rapid carbonization. Possible explanation for these pores is the rapid weight loss of sisal fiber and $\left(\mathrm{NH}_{4}\right)_{2} \mathrm{~B}_{4} \mathrm{O}_{7}$ in this stage isn't in consistent with the rate of fiber dimensional shrinkage and thus results in uniform pores on fiber surface and inner walls. After $\mathrm{KOH}$ activation, in spite of the etched micropores are too small to be observed on the fiber surface from the SEM images, the size and content of mesopores both increase (Fig. $\left.3 \mathrm{a}_{1}-\mathrm{c}_{1}\right)$ with the raise of $\left(\mathrm{NH}_{4}\right)_{2} \mathrm{~B}_{4} \mathrm{O}_{7}$ concentration, which is in good accordance with the TEM (Fig. S3, ESI $\dagger$ ) and nitrogen adsorption-desorption results. The packing density of BN-SAC- $n$ series is in the range of $0.43-0.53 \mathrm{~g} \mathrm{~cm}^{-3}$, comparable to common activated carbons (Table S1, ESI $\dagger$ ).
The Raman and XRD measurements were carried out to further study the structure of BN-SAC- $n$ series, the corresponding results are shown in Fig. $4 \mathrm{a}$ and b, respectively. All samples exhibit two prominent peaks at around $1345 \mathrm{~cm}^{-1}$ assigned to D-bands representing the disordered carbon structure and $1600 \mathrm{~cm}^{-1}$ assigned to G-bands representing the tangential vibration of graphitic carbon..$^{52,53}$ The integrated intensity ratio of $I_{\mathrm{D}} / I_{\mathrm{G}}$ is 0.85 for SAC, 0.91 for BN-SAC-1, 0.94 for BN-SAC-2, and 0.97 for BN-SAC-3, suggesting that high level of $\mathrm{B}, \mathrm{N}$ dual-doping would lead to disordered carbon structure with more defective graphitic crystallites. ${ }^{54}$ Fig. $4 \mathrm{~b}$ shows the XRD patterns of all samples. Two broad diffraction peaks at around $2 \theta=24^{\circ}$ and $44^{\circ}$ appear on each curve, corresponding to (002) and (101) reflections of graphitic carbon, respectively. ${ }^{55}$ Compared with SAC, the BN-SAC- $n$ series show broader peaks and lower peak intensity. As the B, N dual-doping level increases, the peak intensity continues reducing, indicating lower degree of graphitization which is in accordance with the results of Raman spectra.

The X-ray photoelectron spectroscopy (XPS) measurements were carried out to investigate the surface chemical compositions and confirm the incorporation of $\mathrm{B}, \mathrm{N}$ atoms. As shown in Fig. 5a, All XPS survey spectra exhibit similar shape with strong $\mathrm{C}$ and $\mathrm{O}$ signal as well as evident $\mathrm{N}$ and $\mathrm{B}$ signal. Specifically, the contents of C, O, B and $\mathrm{N}$ were estimated and listed in Table S2 (ESI). $\dagger$ As is shown, the content of B is 0.8 , 2.4 and 3.8 at $\%$ and the content of $\mathrm{N}$ is 2.6, 4.0 and 4.5 at $\%$ for BN-SAC-1, BN-SAC-2 and BN-SAC-3, respectively. It is apparent high concentration of $\left(\mathrm{NH}_{4}\right)_{2} \mathrm{~B}_{4} \mathrm{O}_{7}$ aqueous solution increases

Table 1 Porous properties of SAC, BN-SC and BN-SAC- $n$ series

\begin{tabular}{|c|c|c|c|c|c|}
\hline Samples & $S_{\mathrm{BET}}\left(\mathrm{m}^{2} \mathrm{~g}^{-1}\right)$ & $S_{\mathrm{DFT}}\left(\mathrm{m}^{2} \mathrm{~g}^{-1}\right)$ & $V_{\text {total }}\left(\mathrm{cm}^{3} \mathrm{~g}^{-1}\right)$ & $V_{\text {micro }}\left(\mathrm{cm}^{3} \mathrm{~g}^{-1}\right)$ and (pore vol\%) & $V_{\text {meso }}\left(\mathrm{cm}^{3} \mathrm{~g}^{-1}\right)$ and (pore vol\%) \\
\hline BN-SAC-3 & 2017 & 2105 & 1.94 & $0.61(31.4)$ & $1.33(68.6)$ \\
\hline BN-SAC-2 & 1978 & 1995 & 1.69 & $0.60(35.5)$ & $1.09(64.5)$ \\
\hline BN-SAC-1 & 1802 & 1911 & 1.36 & $0.65(47.8)$ & $0.71(52.2)$ \\
\hline SAC & 1017 & 1118 & 0.71 & $0.45(63.4)$ & $0.26(36.6)$ \\
\hline BN-SC & 94 & 122 & 0.28 & $0.02(7.2)$ & $0.26(92.8)$ \\
\hline
\end{tabular}



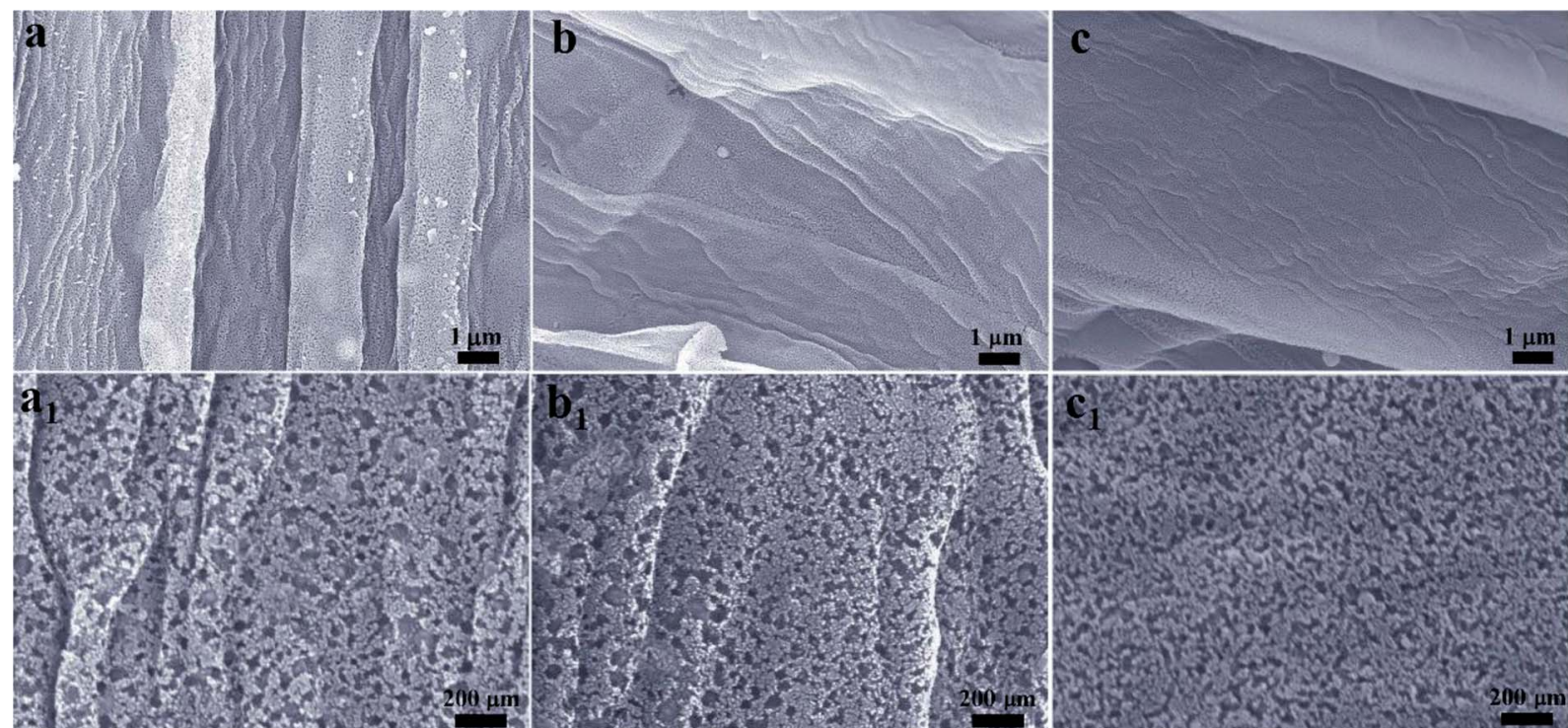

Fig. $3\left(a-c\right.$ and $\left.a_{1}-c_{1}\right)$ SEM images of BN-SAC- $n$ series, (a and $\left.a_{1}\right)$ BN-SAC-3, (b and $\left.b_{1}\right) B N-S A C-2$ and $\left(c\right.$ and $\left.c_{1}\right) B N-S A C-1$

the doping level of both $\mathrm{B}$ and $\mathrm{N}$ atoms. Moreover, the highresolution spectra of B 1s and $\mathrm{N}$ 1s of BN-SAC-3 were fitted to investigate the detailed chemical compositions (Fig. $5 \mathrm{~b}$ and c). It can be seen the B 1s spectrum was deconvolved into two peaks of N-B $(192.2 \mathrm{eV})$ and $\mathrm{B}-\mathrm{CO}_{2}(190.8 \mathrm{eV}) .^{56}$ The $\mathrm{N} 1 \mathrm{~s}$ spectrum could be deconvolved into four peaks at 401.4, 400.5, 399.0 and $398.2 \mathrm{eV}$, corresponding to quaternary $\mathrm{N}$, pyrrolic $\mathrm{N}$, $\mathrm{C}-\mathrm{N}-\mathrm{B}$ and pyridinic $\mathrm{N}$, respectively. ${ }^{57,58}$ In addition to $\mathrm{N}$ and $\mathrm{B}$, the content of $\mathrm{O}$ also increases with the concentration of additive. These introduced functional groups including quaternary $\mathrm{N}$, pyrrolic $\mathrm{N}$, pyridinic $\mathrm{N}, \mathrm{C}-\mathrm{O}, \mathrm{O}-\mathrm{C}=\mathrm{O}$ and $\mathrm{B}-\mathrm{C}$ functionalities have been proven to be effective in facilitating the electron transfer for higher electrical conductivity and providing a great deal of active sites for additional pseudocapacitance..$^{31,34,35,56}$

\subsection{Electrochemical performance of the BN-SAC- $n$}

The electrochemical performance of BN-SAC- $n$ series was first examined in a three-electrode system with $6 \mathrm{M} \mathrm{KOH}$ aqueous solution as electrolyte. Fig. 6a shows the cyclic voltammetry (CV) curves of BN-SAC- $n$ series and SAC at a scan rate of $100 \mathrm{mV} \mathrm{s}^{-1}$, the BN-SAC-3 and BN-SAC-2 with higher mesoporosity (68.6 and $64.5 \%$ ) and larger SSA (2017 and $1978 \mathrm{~m}^{2} \mathrm{~g}^{-1}$ ) both exhibit quasi-rectangular profiles with large loop area, indicating their superior electrical double-layer capacitive behavior at such a high scan rate. While for the BN-SAC-1 with relatively low mesoporosity $(52.2 \%)$ and SSA $\left(1802 \mathrm{~m}^{2} \mathrm{~g}^{-1}\right)$, serious distortion and shrunken loop can be observed on its CV curve at the same scan rate. Besides, all BN-SAC- $n$ series exhibit slight deviation curves at low potentials corresponding to pseudocapacitive behavior induced by the abundant $\mathrm{B}, \mathrm{N}, \mathrm{O}$-containing
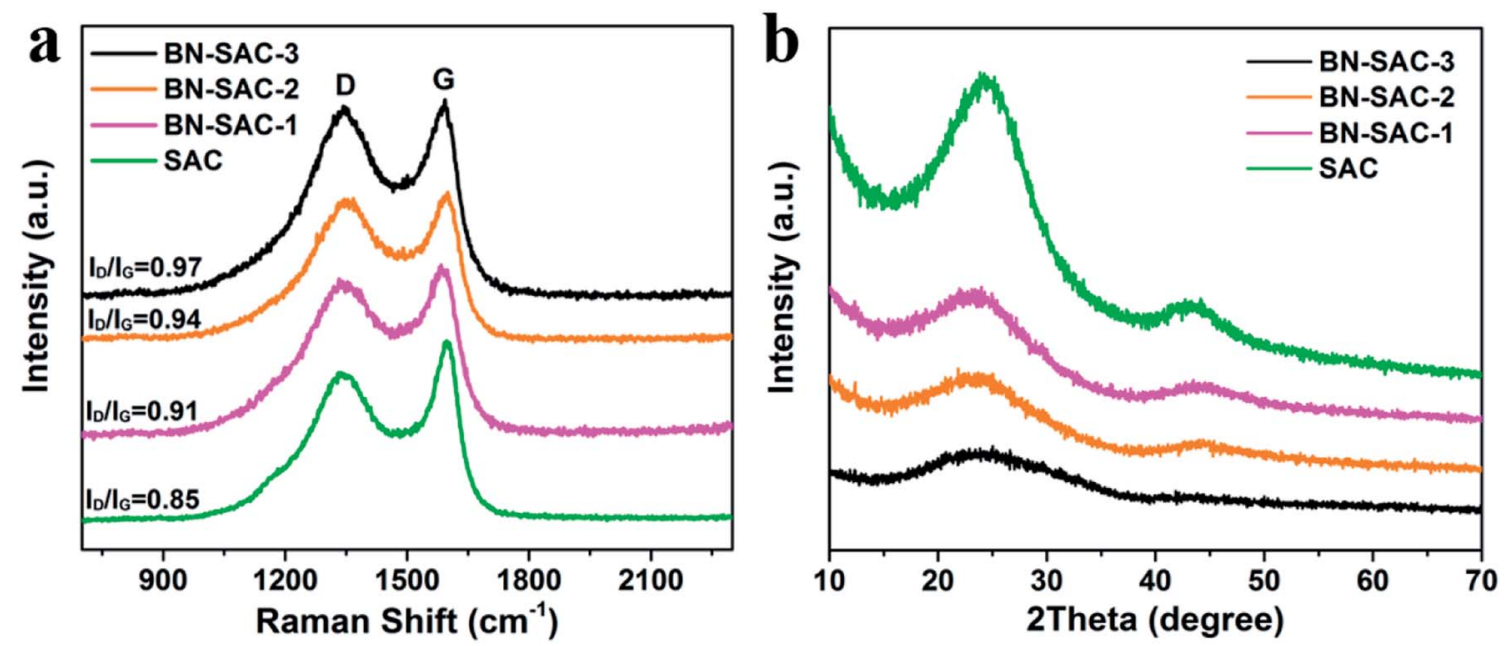

Fig. 4 (a) Raman and (b) XRD spectra of SAC and BN-SAC- $n$ series. 

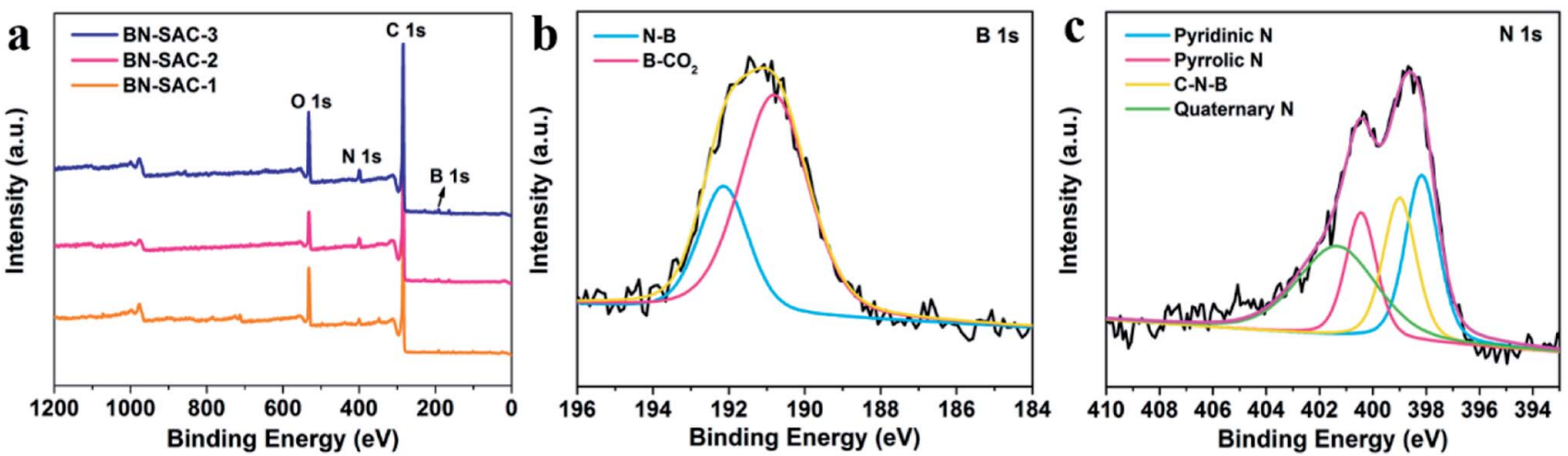

Fig. 5 (a) XPS survey spectrum of BN-SAC- $n$ series; ( $b$ and c) high-resolution B 1s and N 1s spectra of the BN-SAC-3.

functional groups. ${ }^{13}$ In contrast, the un-doped SAC with the lowest mesoporosity $(36.6 \%)$ and SSA $\left(1017 \mathrm{~m}^{2} \mathrm{~g}^{-1}\right)$ prepared through conventional method shows a leaf-shape $\mathrm{CV}$ curve with the smallest loop area, indicating its poor capacitive performance. ${ }^{59}$ These results prove that higher doping level is beneficial for electrical double-layer capacitive behavior, especially at high scan rate. Notably, for the BN-SAC-3 with the highest doping level, it still shows quasi-rectangular CV curve with less distortion (Fig. 6b) even at an ultrahigh scan rate of $400 \mathrm{mV} \mathrm{s}^{-1}$, further demonstrating its excellent rate capability.
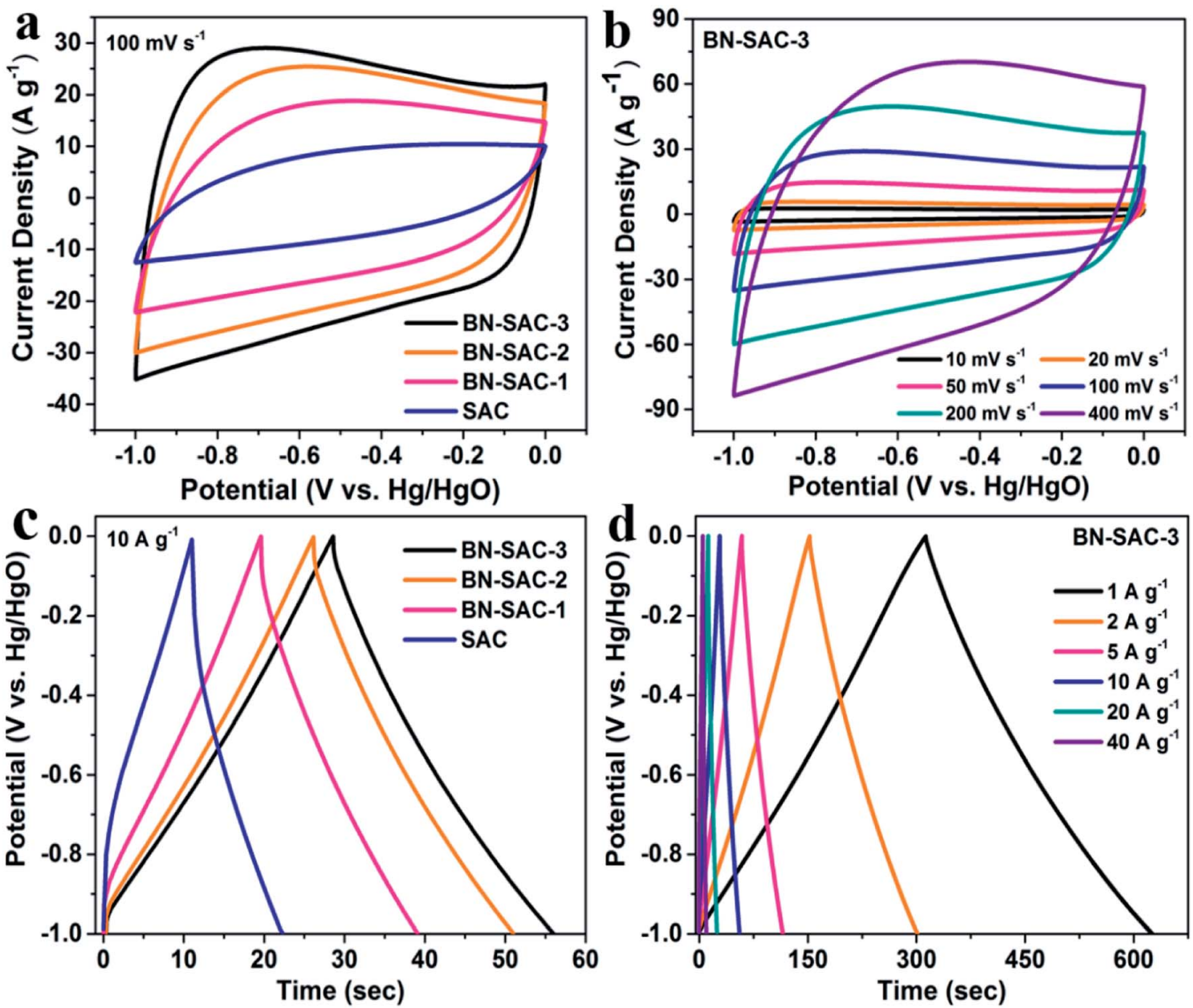

Fig. 6 (a) CV curves of SAC and BN-SAC- $n$ series obtained at a scan rate of $100 \mathrm{mV} \mathrm{s}^{-1}$; (b) CV curves of the BN-SAC-3 obtained at scan rate ranging from $10-400 \mathrm{mV} \mathrm{s}^{-1}$; (c) galvanostatic charge-discharge curves of SAC and BN-SAC- $n$ series measured at a current density of $10 \mathrm{~A} \mathrm{~g}^{-1}$; (d) galvanostatic charge-discharge curves of the BN-SAC-3 at current densities of $1-40 \mathrm{~A} \mathrm{~g}^{-1}$. 
The galvanostatic charge-discharge profiles of all samples obtained at a current density of $10 \mathrm{~A} \mathrm{~g}^{-1}$ are shown in Fig. 6c. All BN-SAC- $n$ series exhibit linear and symmetrical chargedischarge curves ascribed to ideal electrical double-layer capacitive behavior while obvious asymmetrical curve is observed for the SAC due to its dominant micropores with high diffusion resistance. ${ }^{60}$ As the doping level increases, the discharge time prolongs while the IR drop related to the equivalent series resistance (ESR) of the electrode reduces, resulting in significantly increased specific capacitance. Benefitting from its multiscale porous structure with the largest mesoporosity which reduces the inner resistance and facilitates ion diffusion inside the electrode, the BN-SAC-3 exhibits highly linear and symmetrical charge-discharge curve with gradually increasing IR drop from $1 \mathrm{~A} \mathrm{~g}^{-1}$ to $40 \mathrm{~A} \mathrm{~g}^{-1}$, as shown in Fig. 6d and S4. $\dagger^{\dagger}$

Fig. 7a shows the specific capacitance of all samples obtained from the discharge curves at different current densities. The BN-SAC-3 exhibits the highest specific capacitance of $304 \mathrm{~F}$ $\mathrm{g}^{-1}$ at a low current density of $1 \mathrm{~A} \mathrm{~g}^{-1}$ while the BN-SAC-2 and BN-SAC-1 respectively exhibits specific capacitance of 279 and $232 \mathrm{~F} \mathrm{~g}^{-1}$. As the current density increases from $1 \mathrm{~A} \mathrm{~g}^{-1}$ to $60 \mathrm{~A} \mathrm{~g}^{-1}$, the specific capacitance of all samples significantly decrease. However, the sample with higher doping level shows more flat curve with less capacitance loss at high current densities. At an ultrahigh current density of $60 \mathrm{~A} \mathrm{~g}^{-1}$, the BNSAC-3 could still retain a high capacitance of $221 \mathrm{~F} \mathrm{~g}^{-1}(72.6 \%$ of that measured at $1 \mathrm{~A} \mathrm{~g}^{-1}$ ), indicating its best rate capability which is higher than those of biomass-derived porous carbon and heteroatomic doping carbon nanomaterials recently reported in the literatures (Table S3, ESI $†$ ). The BN-SAC-2 and BNSAC-1 respectively shows capacitance of 162 and $73 \mathrm{~F} \mathrm{~g}^{-1}$ at the same current density due to lower SSA and mesoporosity. In contrast, the un-doped SAC exhibits a very low capacitance of 72 $\mathrm{F} \mathrm{g}^{-1}$ at $20 \mathrm{~A} \mathrm{~g}^{-1}$ due to the high diffusion resistance induced by dominant micropores. These results from $\mathrm{CV}$ and galvanostatic charge-discharge profiles indicate that the BN-SAC-3 with the highest doping level exhibits best electrochemical behavior at high scan rate, owing to more functional groups which facilitate the electron transfer and contribute pseudocapacitance. Meanwhile, the multiscale porous structure with the largest mesoporosity and SSA highly promotes the ion diffusion and adsorption/desorption inside the electrodes. To further investigate the electrochemical performance of BN-SAC- $n$ series, electrochemical impedance spectroscopy (EIS) were recorded at open circuit potential in the frequency range of $10^{5}$ to $0.01 \mathrm{~Hz}$. As shown in Fig. 7b, oblate semicircles reflecting the charge transfer resistance are observed in the high frequency region on all Nyquist plots while in the low frequency region nearly vertical lines corresponding to ideal electrical double-layer capacitive behavior appear on all profiles. ${ }^{14}$ As the doping level increases, the equivalent series resistance (ESR) obtained from the real axis intercept decreases, reaching the lowest value of $0.55 \Omega$ for the BN-SAC-3. The change trend of charge transfer resistance obtained from the semicircle diameter is in accordance with the ESR, the measured value is respectively 0.46 , $0.59,0.65$ and $1.83 \Omega$ for BN-SAC-3, BN-SAC-2, BN-SAC- 1 and $\mathrm{SAC}$, proving that $\mathrm{B}, \mathrm{N}$ dual-doping is beneficial for increasing the electrical conductivity. In addition, benefitting from their hierarchical macro-meso-microporous structure with abundant mesopores which facilitate the ion diffusion, the BN-SAC- $n$ series show much higher slope in the low frequency region. Fig. 7c shows the cycling performance of BN-SAC-3 measured at a high current density of $10 \mathrm{~A} \mathrm{~g}^{-1}$ and a negligible capacitance loss $(4.6 \%)$ is observed after 3000 cycles, indicative of its excellent cycling stability. Besides, no obvious electrochemical activation behavior appear during the initial stage of the profile, suggesting that the multiscale porous structure provides easy access for electrolyte ion diffusion while the abundant surface functional groups improve the wettability for quicker ion adsorption/desorption..$^{59}$

\subsection{Electrochemical performance of the BN-SAC-3 in supercapacitors}

SSCs were assembled with the BN-SAC-3 as both positive and negative electrodes to rate its practical performance, the $6 \mathrm{M}$ $\mathrm{KOH}$ and $1 \mathrm{M} \mathrm{TEABF}_{4} / \mathrm{AN}$ solution was respectively employed as the electrolyte. As shown in the Fig. S5, $\uparrow$ for the SSC using $6 \mathrm{M}$ $\mathrm{KOH}$ electrolyte, a stable voltage window could reach $0.9 \mathrm{~V}$ until obvious polarization behavior occur. While for the SSC using $1 \mathrm{M} \mathrm{TEABF} 4 / \mathrm{AN}$ electrolyte, this value is significantly enhanced
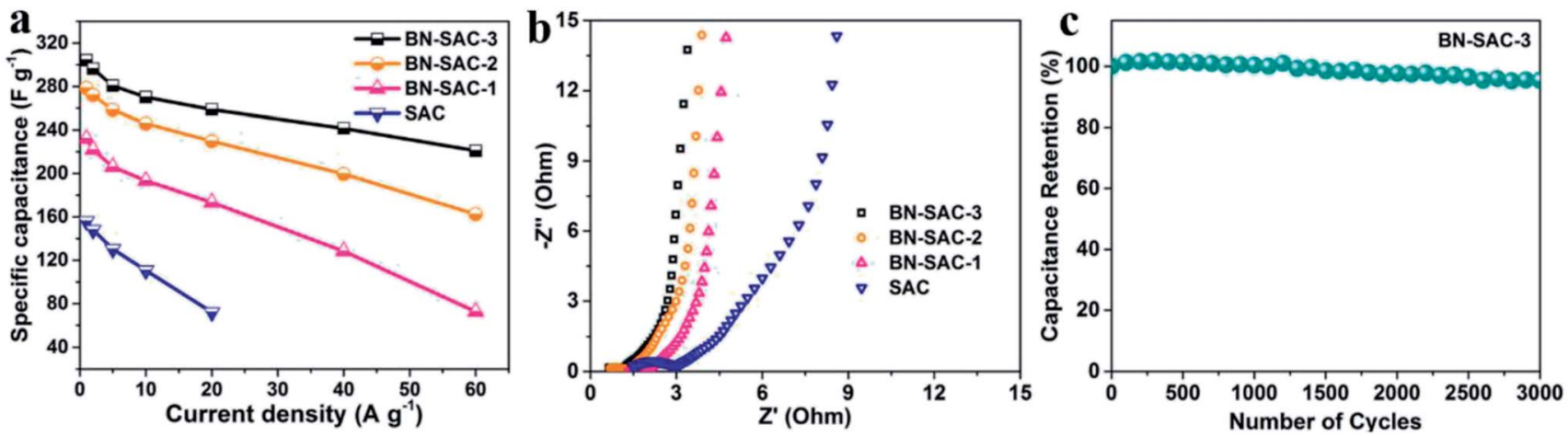

Fig. 7 (a) Rate capability of SAC and BN-SAC- $n$ series; (b) Nyquist plots of SAC and BN-SAC- $n$ series; (c) cycling performance of BN-SAC-3 at a current density of $10 \mathrm{~A} \mathrm{~g}^{-1}$. 
to $2.5 \mathrm{~V}$, showing great potential in enhancing energy and power density of the supercapacitor. As shown in Fig. 8a and b, the supercapacitor exhibits quasi-rectangular shaped CV curves in a wide range of scan rate $\left(20-200 \mathrm{mV} \mathrm{s}^{-1}\right)$ using either electrolyte, indicative of its superior rate capability. Fig. 8c, d and $\mathrm{S}^{\dagger} \dagger$ show the galvanostatic charge-discharge profiles of the device in the two different electrolytes. These curves remain linear and symmetrical characteristics in a wide range of 1-10 $\mathrm{A} \mathrm{g}^{-1}$, further indicating the ideal electrical double-layer capacitive behavior of the as-assembled supercapacitors. Furthermore, the specific capacitance of the devices at various current densities were calculated from the charge-discharge curves, and the results are exhibited in Fig. 8e. At the current density of $1 \mathrm{~A} \mathrm{~g}^{-1}$, the supercapacitor shows a high specific capacitance of $258 \mathrm{~F}$ $\mathrm{g}^{-1}$ in aqueous electrolyte, while in the organic electrolyte it is only $116 \mathrm{~F} \mathrm{~g}^{-1}$ due to much larger electrolyte ions which cannot access into micropores and small mesopores. Nevertheless, the supercapacitor possesses superior rate capability in both aqueous and organic electrolytes, the specific capacitance could still retains $76.4 \%\left(197 \mathrm{~F} \mathrm{~g}^{-1}\right)$ and $61.2 \%\left(71 \mathrm{~F} \mathrm{~g}^{-1}\right)$ of the initial
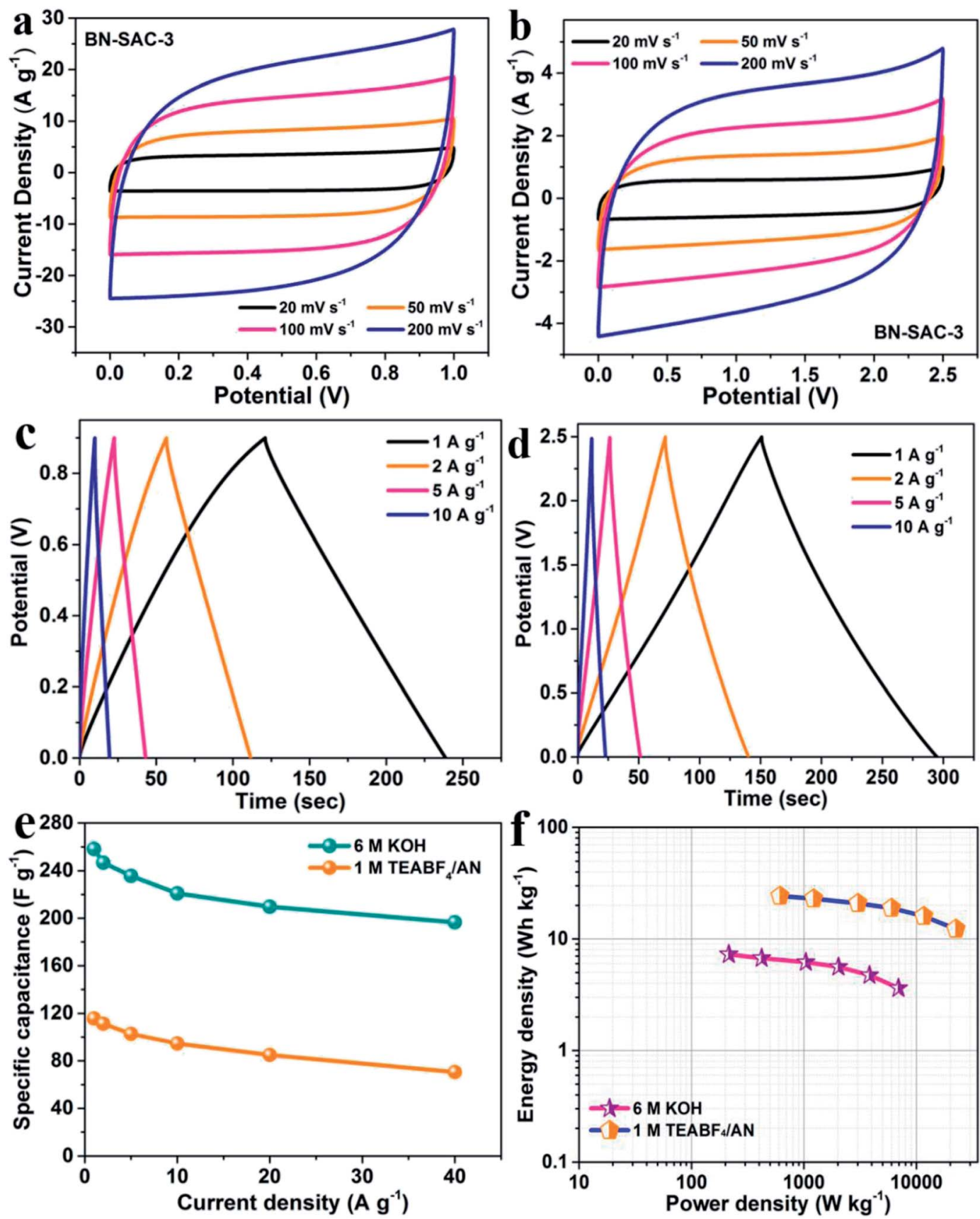

Fig. $8 \mathrm{CV}$ curves of BN-SAC-3 tested in (a) $6 \mathrm{M} \mathrm{KOH}$ and (b) $1 \mathrm{M} \mathrm{TEABF}_{4} / \mathrm{AN}$ electrolytes at scan rates of $20-200 \mathrm{mV} \mathrm{s}^{-1}$; galvanostatic chargedischarge curves of BN-SAC-3 tested in (c) $6 \mathrm{M} \mathrm{KOH}$ and (d) $1 \mathrm{M} \mathrm{TEABF}_{4} / \mathrm{AN}$ electrolytes at current densities of 1-10 A g ${ }^{-1}$; (e) rate capability of $\mathrm{BN}-\mathrm{SAC}-3$; (f) Ragone plots of BN-SAC-3-based symmetric supercapacitor with $6 \mathrm{M} \mathrm{KOH}$ and $1 \mathrm{M}$ TEABF $4 / A N$ as electrolyte, respectively. 
capacitance at the current density of $40 \mathrm{~A} \mathrm{~g}^{-1}$, respectively. The Ragone plots of the supercapacitor based on BN-SAC-3 is shown in Fig. 8f. Benefitting from the larger voltage window in $1 \mathrm{M}$ $\mathrm{TEABF}_{4} / \mathrm{AN}$ electrolyte, the maximum energy density of the device can reach to $24.3 \mathrm{~W} \mathrm{~h} \mathrm{~kg}^{-1}$ at a power density of $612.8 \mathrm{~W}$ $\mathrm{kg}^{-1}$, which is much higher than that in $6 \mathrm{M} \mathrm{KOH}$ electrolyte (7.3 $\mathrm{W} \mathrm{h} \mathrm{kg}^{-1}$ at $215 \mathrm{~W} \mathrm{~kg}^{-1}$ ). Besides, the energy density could still retain as high as $12.3 \mathrm{~W} \mathrm{~h} \mathrm{~kg}^{-1}\left(3.6 \mathrm{~W} \mathrm{~h} \mathrm{~kg}^{-1}\right.$ in aqueous electrolyte) when the power density reaches its maximum value of $22.45 \mathrm{~kW} \mathrm{~kg}^{-1}$ (6.9 $\mathrm{kW} \mathrm{kg}^{-1}$ in aqueous electrolyte). In addition, the SSC using $6 \mathrm{M} \mathrm{KOH}$ and $1 \mathrm{M} \mathrm{TEABF}_{4} / \mathrm{AN}^{\mathrm{N}}$ electrolyte respectively shows negligible capacitance loss of 5.2 and $3.8 \%$ after 3000 cycles (Fig. S7†), indicative of their excellent cycling stability.

\section{Conclusion}

In conclusion, novel $\mathrm{B}, \mathrm{N}$ dual-doped ACs with hierarchical macro-meso-microporous structure for high-rate EDLC electrodes were prepared from $\left(\mathrm{NH}_{4}\right)_{2} \mathrm{~B}_{4} \mathrm{O}_{7}$-containing sisal fibers through a facile strategy combining low-pressure rapid carbonization and $\mathrm{KOH}$ activation. As the concentration of $\mathrm{B}$, $\mathrm{N}$-containing reagent increases, the doping level of $\mathrm{B}$ and $\mathrm{N}$, the SSA and the mesoporosity of the BN-SAC- $n$ series all greatly increase, indicating the $\left(\mathrm{NH}_{4}\right)_{2} \mathrm{~B}_{4} \mathrm{O}_{7}$ effectively promotes the formation of mesopores and multiscale porous structure due to the rapid gas evaporation during its decomposition, in addition to endowing the BN-SAC with $\mathrm{B}, \mathrm{N}$ dual-doping. Benefitting from the multiscale hierarchical structure built up by inherent cellular channels, mesopores on tracheid walls and etched micropores, the BN-SAC exhibit both high SSA and mesoporosity. Besides, the $\mathrm{B}, \mathrm{N}$ dual-doping provides the $\mathrm{BN}$ SAC with abundant functional groups for additional pseudocapacitance and improves their electrical conductivity and surface accessibility. With the highest SSA $\left(2017 \mathrm{~m}^{2} \mathrm{~g}^{-1}\right)$, mesoporosity (68.6\%) and doping level of B, $\mathrm{N}$ atoms (3.8 and 4.5 at\%, respectively), the BN-SAC-3 exhibits excellent electrochemical performance in both aqueous and organic electrolyte. For three-electrode test, the BN-SAC-3 shows a high specific capacitance of $304 \mathrm{~F} \mathrm{~g}^{-1}$ at $1 \mathrm{~A} \mathrm{~g}^{-1}$, which could still retain $72.6 \%$ when the current density increases to $60 \mathrm{~A} \mathrm{~g}^{-1}$. After assembling into SSCs, the BN-SAC-3 shows a maximum specific capacitance of $258 \mathrm{~F} \mathrm{~g}^{-1}$ at $1 \mathrm{~A} \mathrm{~g}^{-1}$ in aqueous electrolyte (116 $\mathrm{F} \mathrm{g}^{-1}$ in organic electrolyte) with a high retention of $76.4 \%$ at $40 \mathrm{~A} \mathrm{~g}^{-1}$ (61.2\% in organic electrolyte), and delivers a maximum energy density of $24.3 \mathrm{~W} \mathrm{~h} \mathrm{~kg}^{-1}$ at a power density of $612.8 \mathrm{~W} \mathrm{~kg}^{-1}$ in organic electrolyte. This work provides an effective and economic method for the synthesis of hierarchical macro-meso-microporous ACs for high-performance EDLC electrodes and is expected to be applied on other biomasses on a large scale.

\section{Conflicts of interest}

There are no conflicts to declare.

\section{Acknowledgements}

This work was financially supported by the National Key R\&D Program of China (No. 2017YFB1103500), the National Natural Science Foundation of China (No. 51302220, 51672218 and 51632007) and the Ministry of Business, Innovation and Employment Endeavour Fund of New Zealand (No. 3000033429).

\section{References}

1 Z. Yang, J. Tian, Z. Yin, C. Cui, W. Qian and F. Wei, Carbon, 2018, 141, 467-480.

2 H. Wu, Y. Zhang, L. Cheng, L. Zheng, Y. Li, W. Yuan and X. Yuan, Energy Storage Materials, 2016, 5, 8-32.

3 J. Zhang, L. Jin, J. Cheng and H. Hu, Carbon, 2013, 55, 221232.

4 X. He, R. Li, J. Qiu, K. Xie, P. Ling, M. Yu, X. Zhang and M. Zheng, Carbon, 2012, 50, 4911-4921.

5 F. Huang and D. Chen, Energy Environ. Sci., 2012, 5, 58335841.

6 P. Sun, Z. Deng, P. Yang, X. Yu, Y. Chen, Z. Liang, H. Meng, W. Xie, S. Tan and W. Mai, J. Mater. Chem. A, 2015, 3, 1207612080.

7 Z. Wu, S. Yang, L. Zhang, J. B. Wagner, X. Feng and K. Müllen, Energy Storage Materials, 2015, 1, 119-126.

8 L. J. Wang, M. F. El-Kady, S. Dubin, J. Y. Hwang, Y. Shao, K. Marsh, B. McVerry, M. D. Kowal, M. F. Mousavi and R. B. Kaner, Adv. Energy Mater., 2015, 5, 1500786.

9 G. Wang, L. Zhang and J. Zhang, Chem. Soc. Rev., 2012, 41, 797-828.

10 L. Zhang, F. Zhang, X. Yang, K. Leng, Y. Huang and Y. Chen, Small, 2013, 9, 1342-1347.

11 H. Wu, Y. Zhang, W. Yuan, Y. Zhao, S. Luo, X. Yuan, L. Zheng and L. Cheng, J. Mater. Chem. A, 2018, 6, 16617-16626.

12 Y. Zhai, Y. Dou, D. Zhao, P. F. Fulvio, R. T. Mayes and S. Dai, Adv. Mater., 2011, 23, 4828-4850.

13 Z. Jin, X. Yan, Y. Yu and G. Zhao, J. Mater. Chem. A, 2014, 2, 11706-11715.

14 H. Wu, L. Cheng, Y. Zhang, W. Yuan and L. Zheng, Carbon, 2017, 116, 518-527.

15 Y. Cao, K. Wang, X. Wang, Z. Gu, Q. Fan, W. Gibbons, J. D. Hoefelmeyer, P. R. Kharel and M. Shrestha, Electrochim. Acta, 2016, 212, 839-847.

16 M. Sevilla and A. B. Fuertes, ChemSusChem, 2016, 9, 18801888.

17 X. Fan, C. Yu, J. Yang, Z. Ling, C. Hu, M. Zhang and J. Qiu, Adv. Energy Mater., 2015, 5, 1401761.

18 D. Shan, J. Yang, W. Liu, J. Yan and Z. Fan, J. Mater. Chem. A, 2016, 4, 13589-13602.

19 H. Wang, Z. Xu, A. Kohandehghan, Z. Li, K. Cui, X. Tan, T. J. Stephenson, C. K. King'ondu, C. M. Holt and B. C. Olsen, ACS Nano, 2013, 7, 5131-5141.

20 C. Péan, C. Merlet, B. Rotenberg, P. A. Madden, P.-L. Taberna, B. Daffos, M. Salanne and P. Simon, ACS Nano, 2014, 8, 1576-1583. 
21 A. C. Forse, J. M. Griffin, C. Merlet, J. Carretero-Gonzalez, A.-R. O. Raji, N. M. Trease and C. P. Grey, Nat. Energy, 2017, 2, 16216.

22 F. Zhang, T. Liu, M. Li, M. Yu, Y. Luo, Y. Tong and Y. Li, Nano Lett., 2017, 17, 3097-3104.

23 M. H. Ervin, Nanotechnology, 2015, 26, 234003.

24 Q. Zhao, X. Wang, J. Liu, H. Wang, Y. Zhang, J. Gao, Q. Lu and H. Zhou, Electrochim. Acta, 2015, 154, 110-118.

25 W. Yuan, L. Cheng, Y. Zhang, Y. Li, X. Guo, H. Wu and L. Zheng, Ceram. Int., 2017, 43, 11563-11568.

26 W. Yuan, Y. Zhang, L. Cheng, H. Wu, L. Zheng and D. Zhao, J. Mater. Chem. A, 2016, 4, 8932-8951.

27 H. Jiang, X. Cai, Y. Qian, C. Zhang, L. Zhou, W. Liu, B. Li, L. Lai and W. Huang, J. Mater. Chem. A, 2017, 5, 2372723736.

28 E. Senokos, V. Reguero, L. Cabana, J. Palma, R. Marcilla and J. J. Vilatela, Adv. Mater. Technol., 2017, 2, 1600290.

29 H. Peng, Q. Li and T. Chen, Industrial applications of carbon nanotubes, William Andrew, 2016.

30 P. Simon and Y. Gogotsi, Acc. Chem. Res., 2012, 46, 10941103.

31 H. M. Jeong, J. W. Lee, W. H. Shin, Y. J. Choi, H. J. Shin, J. K. Kang and J. W. Choi, Nano Lett., 2011, 11, 2472-2477.

32 Y. Chen, X. Zhang, D. Zhang, P. Yu and Y. Ma, Carbon, 2011, 49, 573-580.

33 X. Rui, Q. Yan, M. Skyllas-Kazacos and T. M. Lim, J. Power Sources, 2014, 258, 19-38.

34 J. Hou, C. Cao, F. Idrees and X. Ma, ACS Nano, 2015, 9, 25562564.

35 C. Wang, Z. Guo, W. Shen, Q. Xu, H. Liu and Y. Wang, Adv. Funct. Mater., 2014, 24, 5511-5521.

36 Y. Zheng, Y. Jiao, L. Ge, M. Jaroniec and S. Z. Qiao, Angew. Chem., 2013, 125, 3192-3198.

37 J. P. Paraknowitsch and A. Thomas, Energy Environ. Sci., 2013, 6, 2839-2855.

38 Z. Hu, S. Li, P. Cheng, W. Yu, R. Li, X. Shao, W. Lin and D. Yuan, J. Mater. Sci., 2016, 51, 2627-2633.

39 K. Qu, Y. Zheng, Y. Jiao, X. Zhang, S. Dai and S. Z. Qiao, Adv. Energy Mater., 2017, 7, 1602068.

40 M. Wang, Y. Yang, Z. Yang, L. Gu, Q. Chen and Y. Yu, Adv. Sci., 2017, 4, 1600468.
41 Q. Xia, H. Yang, M. Wang, M. Yang, Q. Guo, L. Wan, H. Xia and Y. Yu, Adv. Energy Mater., 2017, 7, 1701336.

42 X. Liu and M. Antonietti, Adv. Mater., 2013, 25, 6284-6290.

43 G. P. Hao, A. H. Lu, W. Dong, Z. Y. Jin, X. Q. Zhang, J. T. Zhang and W. C. Li, Adv. Energy Mater., 2013, 3, 14211427.

44 C. Falco, J. M. Sieben, N. Brun, M. Sevilla, T. Van der Mauelen, E. Morallon, D. Cazorla-Amoros and M. M. Titirici, ChemSusChem, 2013, 6, 374-382.

45 L. Sun, C. Tian, Y. Fu, Y. Yang, J. Yin, L. Wang and H. Fu, Chem.-Eur. J., 2014, 20, 564-574.

46 Y. Fang, Y. Lv, R. Che, H. Wu, X. Zhang, D. Gu, G. Zheng and D. Zhao, J. Am. Chem. Soc., 2013, 135, 1524-1530.

47 L. Wang, G. Mu, C. Tian, L. Sun, W. Zhou, P. Yu, J. Yin and H. Fu, ChemSusChem, 2013, 6, 880-889.

48 M. Dizbay-Onat, U. K. Vaidya and C. T. Lungu, Ind. Crops Prod., 2017, 95, 583-590.

49 V. Arthanarieswaran, A. Kumaravel and M. Kathirselvam, Mater. Des., 2014, 64, 194-202.

50 M. Dizbay-Onat, E. Floyd, U. K. Vaidya and C. T. Lungu, Fibers Polym., 2018, 19, 805-811.

51 B. Li, Energy Environ. Sci., 2016, 9, 102-106.

52 J. Yang, X. Zhou, D. Wu, X. Zhao and Z. Zhou, Adv. Mater., 2017, 29, 1604108.

53 Y. Wang, C. Wang, H. Guo, Y. Wang and Z. Huang, RSC Adv., 2017, 7, 1588-1592.

54 L. Zhang, G. Xia, Z. Guo, X. Li, D. Sun and X. Yu, Int. J. Hydrogen Energy, 2016, 41, 14252-14260.

55 M. Biswal, A. Banerjee, M. Deo and S. Ogale, Energy Environ. Sci., 2013, 6, 1249-1259.

56 Z. Ling, Z. Wang, M. Zhang, C. Yu, G. Wang, Y. Dong, S. Liu, Y. Wang and J. Qiu, Adv. Funct. Mater., 2016, 26, 111-119.

57 Z. S. Wu, A. Winter, L. Chen, Y. Sun, A. Turchanin, X. Feng and K. Müllen, Adv. Mater., 2012, 24, 5130-5135.

58 M. Wang, Z. Yang, W. Li, L. Gu and Y. Yu, Small, 2016, 12, 2559-2566.

59 Z. Li, L. Zhang, B. S. Amirkhiz, X. Tan, Z. Xu, H. Wang, B. C. Olsen, C. M. B. Holt and D. Mitlin, Adv. Energy Mater., 2012, 2, 431-437.

60 E. Raymundo-Piñero, M. Cadek and F. Béguin, Adv. Funct. Mater., 2009, 19, 1032-1039. 